\title{
Interactive comment on "Assessment of land use impact on hydraulic threshold conditions for gully head cut initiation" by Aliakbar Nazari Samani et al.
}

Anonymous Referee \#1

Received and published: 10 March 2016

This is an interesting paper to assess the impacts of land use on type of flow, the threshold shear stress for surface erosion and gully initiation threshold. The overall presentation is well structured and clear. The conclusions are useful for the development of physically based erosion models. However, this paper leaves out some details that should be properly explained. Specific comments and some technical corrections are discussed in the following.

Specific comments

1) Lines $114-116$ says that "the experiment was started with low discharge ( 0.75 liter per second) then increased to high discharge so that the head cut could be observed". First, information about how the discharge increased from low to high discharge grad- 
ually is better to be given here. Further, in my view, the three experiments are better to have same runs and same discharge in each run so that the experiments can be more comparable and scientific. However, this study designed different runs and discharges for the three experiment land (Table 2). Please explain why design in this way. 2) Line 144-146 states that "A total of four, seven and five runs were conducted on the rangeland, dry farming and abandoned land respectively to reach the mentioned threshold of head cut initiation". But there are 6 runs shown in Table 3 for the dry farming land. Please check. 3) Lines 154-156 stated "the land covers in dry farming and abandoned lands increased the surface roughness and indirectly caused the decrease of Re by decreasing the flow velocity." So my question is that the flow velocity used to calculate $R e$ in this study is the measured values or calculated by equation (1)? 4) Few references cited in manuscript are from last five years. Please read more literatures in recent years and modify the introduction.

\section{Technical corrections}

1) The mathematical symbols in the formulae and in the paper should keep consistent. The "U" in formula (1) is in italics while is in non-italics in other places (say line 125). The "b" in equation (7) and on line 137 is inconsistent. 2) The Froude number is expressed using "F" on line 126 while using "Fr" on line 150. Please check the whole paper and unify their form. 3) Experiments of the three kinds lands are better to be separated with a horizontal line in Table 2 and Table 3 so that readers can distinguish which discharges or runs corresponding to which land use type more easily. 4) please check the sentence on lines 168-170 "However, the discharge needed to create enough energy for incision in rangeland was more than was required for dry farming and abandoned lands." 5 The $\mathrm{Kc}$ in equation (7), c is subscript or not? Please check.

Interactive comment on Hydrol. Earth Syst. Sci. Discuss., doi:10.5194/hess-2015-462, 2016. 